\title{
Russet Sparrows spot alien chicks from their nests
}

\author{
Juan Huo ${ }^{1}$, Canchao Yang ${ }^{1 *}$, Tongping Su², Wei Liang ${ }^{1 *}$ (D) and Anders Pape Møller ${ }^{3}$
}

\begin{abstract}
Background: In coevolutionary interactions between brood parasites and their hosts, host parents are under strong selection to evolve defenses against parasitism. Egg rejection is an efficient and common defense against parasitism, although some apparently suitable hosts do not reject cuckoo eggs.

Methods: Sparrows Ploceidae are widespread throughout the Old World, and they have a suitable diet for rearing cuckoos, but still they are rarely exploited by brood parasites. To solve such puzzle, we conducted artificial parasitism and cross-fostering experiments in Russet Sparrow (Passer cinnamomeus).

Results: The present study showed that Russet Sparrows have no egg recognition ability, but recognize their own nestlings and eject alien chicks or starve them to death. They may use visual cues in chick recognition, although they accept sister species Tree Sparrow (Passer montanus).

Conclusions: By rejecting nestlings of foreign species, Russet Sparrows have succeeded to escape from the brood parasitism by cuckoos and other parasites. Our studies shed light on the puzzle why some species are not utilized by cuckoo parasites as hosts.
\end{abstract}

Keywords: Chick recognition, Coevolution, Cross-fostering, Egg recognition, Passer cinnamomeus

\section{Background}

Interactions between brood parasites and their hosts are regarded as a model system for the study of coevolution (Davies 2000; Soler 2014). Brood parasites lay their eggs in hosts' nests and subsequently transfer the cost of parental care to the hosts. This selects for the evolution of defenses in hosts, which in turn selects for reciprocal counter-adaptations in the parasite. Although there is a vast literature on the reciprocal adaptations of brood parasites and their hosts at the pre-laying (Davies and Welbergen 2009; Feeney et al. 2012), egg (Davies and Brooke 1988; Starling et al. 2006; Spottiswoode and Stevens 2010; Yang et al. 2010, 2016a; Stoddard and Stevens 2011) and chick stages (Langmore et al. 2003; de Mársico et al. 2012; Yang et al. 2015b), less is known about how the coevolution between parasites and hosts reach the current outcome of these arms races (Kilner and Langmore

\footnotetext{
*Correspondence: ccyang@hainnu.edu.cn; liangwei@hainnu.edu.cn ${ }^{1}$ Ministry of Education Key Laboratory for Ecology of Tropical Islands, College of Life Sciences, Hainan Normal University, Haikou 571158, China Full list of author information is available at the end of the article
}

2011). In particular, relatively few studies have investigated whether host defenses can result in escaping from brood parasitism.

Although the coevolutionary outcome of an arms race is difficult to elucidate strong indirect evidence has been found to demonstrate that some hosts have defeated brood parasites by maintaining strong anti-parasitism defenses such as egg rejection despite a lack of current parasitism. Such evidence has been obtained for several suspected former hosts of cuckoos. For example, the Hume's Leaf Warbler (Phylloscopus humei), which is not currently parasitized, shows high inter-clutch variation in egg size and rejects eggs that differ in size to their own clutch, thus preventing egg matching by the parasite and allowing successful prevention of parasitism (Marchetti 2000).

Compared to Hume's Leaf Warbler, other potential hosts in Asia present more of a conundrum if they lack egg rejection behavior, yet they are not exploited by brood parasites. One explanation is that these hosts may have won the arms race by showing specific defenses at 
other stages (e.g., chick stage: Grim 2006) of the breeding cycle. For example, the Least Flycatchers (Empidonax minimus) experience rates of parasitism six times lower than sympatric Yellow Warblers (Dendroica petechial) (Briskie et al. 1990). This difference was attributed in large part to the more aggressive and effective nest defense by Least Flycatchers (Briskie et al. 1990). Although most studies have been done on coevolutionary interactions at the pre-laying or egg stages of the breeding cycle, hosts may also show defenses at the chick stage by deserting (Langmore et al. 2003; Grim 2007) or evicting (Sato et al. 2010; Yang et al. 2015b) alien nestlings. However, without studying several, and ideally all, breeding stages (e.g., prelaying, egg, chick), it is hard to tell why some hosts escape parasitism or reduce its rate substantially (Briskie et al. 1990; Grim et al. 2011; Li et al. 2016).

Sparrow species (Passer spp.) are widespread across the Old World and feed their offspring on insects (Baumgartner 1937; Seel 2008; Girard et al. 2012; Yang et al. 2015a), which should provide a suitable diet for cuckoo chicks. Generally their egg recognition capacities are absent or negligible and some of them (e.g. House Sparrow $P$. domesticus) were suggested to be unsuitable model species for egg rejection experiments on a global scale (Manna et al. 2017). However, they have never been used as hosts by any parasitic cuckoo (Moksnes and Røskaft 1995; Yang et al. 2012b) and till now this puzzle has not been reasonably explained. These include a variety of sparrow species such as Tree Sparrows, House Sparrows, and Russet Sparrow (Passer cinnamomeus). There have been two hypotheses that tried to explain this puzzle. First, hosts may escape parasitism by breeding in urban areas as a specific adaptation or a byproduct (Liang et al. 2013). Second, they may build nest in small cavities that exclude larger parasites (Davies 2000). However, none of these explanations presents a satisfactory solution to this puzzle. On one hand, some host species living in urban areas are exploited by brood parasites (Yang et al. 2012b). On the other hand, in addition to cavity nests, sparrows also build open nests in trees (Yang et al. 2015a), and most importantly cavity nests cannot prevent small parasites (e.g. Asian Emerald Cuckoo Chrysococcyx maculatus) from entering. Additionally, even medium to large sized cuckoos can enter nest boxes to parasitize cavitynesting hosts, including Common Redstart (Phoenicurus phoenicurus) (Samaš et al. 2016), tits (Parus spp.) and flycatchers (Ficedula spp.) (Deng 2013; Grim et al. 2014; Liang et al. 2016). Therefore, all the current explanations cannot resolve why sparrows have never been utilized as hosts by any parasitic cuckoo, even though they are abundant and widespread.

Here we conducted parasitic experiments at both egg and chick stages of the breeding cycle to investigate the egg and chick recognition abilities of Russet Sparrow, a widespread potential cuckoo host but not currently utilized by any parasitic cuckoos. Because nest sanitation was hypothesized to be a pre-adaptation of egg recognition (Rothstein 1975; Moskát et al. 2003) that hosts generally show stronger recognition toward non-egg-shaped objects than egg-shaped objects (Yang et al. 2015c), we also tested nest sanitation behavior in Russet Sparrows. This study aims to determine whether egg or chick stage defenses can explain the lack of parasitism of this species by brood parasites.

\section{Methods}

\section{Study area and species}

Experiments on Russet Sparrows were conducted in Kuankuoshui (KKS) National Nature Reserve during April-August 2013. KKS $\left(28^{\circ} 10 \mathrm{~N}, 107^{\circ} 10^{\prime} \mathrm{E}\right)$ lies in a subtropical evergreen broadleaf forest in southwestern China. The mean annual temperature and precipitation are $13.4^{\circ} \mathrm{C}$ and $1330 \mathrm{~mm}$, respectively (Yang et al. 2010).

The Old World sparrows are among the most familiar of all bird species (Allende et al. 2001). The Russet Sparrow, was formerly recognized as $P$. rutilans (Mlíkovský 2011; also see Yang et al. 2012a). The Russet Sparrow is a sexually dimorphic species and prefers light woodland, although they may sometimes be found in towns and agricultural areas (Yang et al. 2012a). They mainly use dry grasses for nesting and the nest structures depend on the cavity size they choose. In the present study all nests of Russet Sparrows for experiments were inside nest boxes.

\section{Experiments of artificial parasitism}

Artificial parasitism during the egg stage was performed in sparrow nests on the day after clutch completion or at the beginning of incubation. We artificially parasitized the nests with model eggs, models that were coin-shaped or stick-shaped, or real eggs of alien species from crossfostering experiment (see below). The use of stick and coin models allowed us to test whether Russet Sparrow shows basic nest sanitation behavior, which is believed to be a pre-requisite for the evolution of egg rejection (Guigueno and Sealy 2012; Yang et al. 2015c). Each sparrow nest received one of the following treatments: (1) blue model eggs; (2) model coins; and (3) model sticks. Model eggs, model coins and model sticks were all made of polymer clay with a mass of ca. $1.45 \mathrm{~g}$ similar to but slightly lighter than that of sparrow eggs $(1.78 \pm 0.12 \mathrm{~g}$, $n=10$ ). Model coins were pie-shaped with a diameter of ca. $22 \mathrm{~mm}$ and ca. $6 \mathrm{~mm}$ in thickness while model sticks were cylinder-shaped with a length of ca. $21 \mathrm{~mm}$ and ca. $11 \mathrm{~mm}$ diameter in cross section. For each nest, one egg or model was inserted into the nests of sparrows, and they were monitored on a daily basis for 6 days. 
Results of the experiments were classified as acceptance (alien objects are warm and intact and being incubated with eggs) or rejection (alien objects gone or left cold in the nest) (Yang et al. 2010). No experimental nests were deserted (Table 1).

\section{Cross-fostering experiments}

In total alien eggs from 10 sympatric species were used in cross-fostering experiments for Russet Sparrow. Eggs ( $n=15$ nests) or newly hatched chicks ( $n=2$ nests) of similar mass were inserted into sparrow nests and their fate was monitored daily. We chose these 10 alien species because they are sympatric with Russet Sparrow in the same study area and their nests can be found during the breeding season of the sparrow. However, the choice is random and alien chicks with similar body mass as Russet Sparrow were used during the experiment. Nests of Russet Sparrow received one of three treatments: (1) cuckoo group-host nests were manipulated to contain one cuckoo chick; (2) foreign group-host nests were manipulated to contain two alien chicks of a non-cuckoo species; or (3) mixed group-each nest was manipulated to two non-cuckoo alien chicks and two host chicks. Considering the ethical problem of potential risk of death in alien chicks, for each alien species we only used two samples (i.e. two nests) or one sample (i.e. one nest). Furthermore, two kinds of control groups were included: (1) manipulated control-cross-fostering of the same sparrow species between different clutches; and (2) non-manipulated control-visits without crossfostering manipulation. Small portable far infrared cameras $(108.9 \mathrm{~mm} \times 32.8 \mathrm{~mm} \times 12.5 \mathrm{~mm}$ in size and $90 \mathrm{~g}$ in weight, JWD DV-58, Jingwah Digital Technology Co., Ltd., Shenzhen, China) were set up inside experimental nest boxes to monitor feeding frequency of host chicks and alien chicks by host parents. Feeding frequency was summarized from video records to investigate feeding preferences by sparrow parents if any existed. We recorded host provisioning rates for $48 \mathrm{~h}$ of video recordings for the cuckoo group and $30 \mathrm{~h}$ for the foreign group, and $108 \mathrm{~h}$ for the mixed group. For the mixed group, host chicks with parasites of Ashy-throated Parrobtill

Table 1 Outcome of experimental parasitism in Russet Sparrows

\begin{tabular}{lccc}
\hline Parasite model egg & Accepted & Ejected & Total \\
\hline Blue model egg & $11(100.0)$ & 0 & 11 \\
Blue model coin & $5(27.8)$ & 13 & 18 \\
Blue model stick & $6(50.0)$ & 6 & 12 \\
Real alien egg & $10(100.0)$ & 0 & 10 \\
\hline
\end{tabular}

${ }^{a}$ Real eggs of 10 alien species from cross-fostering experiment. Numbers in brackets refer to the percentage of acceptance (\%)
(Paradoxornis alphonsianus), Yellow-throated Bunting and Red-billed Leiothrix (Leiothrix lutea) were recorded. For the foreign group, video records included Brownbreasted Bulbul (Pycnonotus xanthorrhous), Greenbacked Tit (Parus monticolus), Ashy-throated Parrotbill, and Red-billed Leiothrix. For the cuckoo group, Lesser Cuckoo (Cuculus poliocephalus) was recorded. The average feeding frequency per chick per hour was calculated for each observed nest and the results are shown in Fig. 3.

\section{Statistical analyses}

IBM SPSS Statistics 20.0 for Windows (IBM Inc.) was used for the calculations and the data were presented as mean \pm SD. The average feeding frequency of hosts and parasites in the mixed group was calculated and compared by paired sample $t$ test. Scatter plots were generated for the feeding frequency with days to present the tendency of feeding.

\section{Results}

In response to artificial parasitism at the egg stage, Russet Sparrow accepted 100\% of model eggs and real eggs (from cross-fostering experiments). By contrast, Russet Sparrows accepted 27.8\% of model coins and 50\% of model sticks. In the cross-fostering experiment, all dead chicks died in Russet Sparrow nests except one case of Tree Sparrow (Passer montanus) chick (Figs. 1, 2). No rejection behavior was detected in control groups. In two cases of the mixed groups, Russet Sparrow own chicks also died. All dead chicks died because of starvation or nest desertion except one case that a female sparrow ejected one live chick of yellow-throated bunting (Emberiza elegans) from its nest (Fig. 1). Survival time of rejected chicks varied from two to 14 days (Fig. 2). Only one case was confirmed as ejection because Russet Sparrows did not identify alien chicks during begging as alien chicks disappeared unexpectedly at any time during 13 days (two to 14 days) before we detected the disappearance.

In the cross-fostering experiment, host parents did not feed parasites for 2 days up to 15 days depending on parasite species (Fig. 2). Furthermore, the frequency of feeding of parasites in foreign and cuckoo groups decreased as they grew larger and finally hosts stopped feeding them (Fig. 3). However, host parents kept on feeding their own nestlings but abandoned alien nestlings in the mixed group. Therefore, the parasite chicks received much less food than host chicks in the mixed group and finally starve to death $(t=4.62, \mathrm{df}=4, p=0.01$, paired sample $t$ test; Fig. 3). 


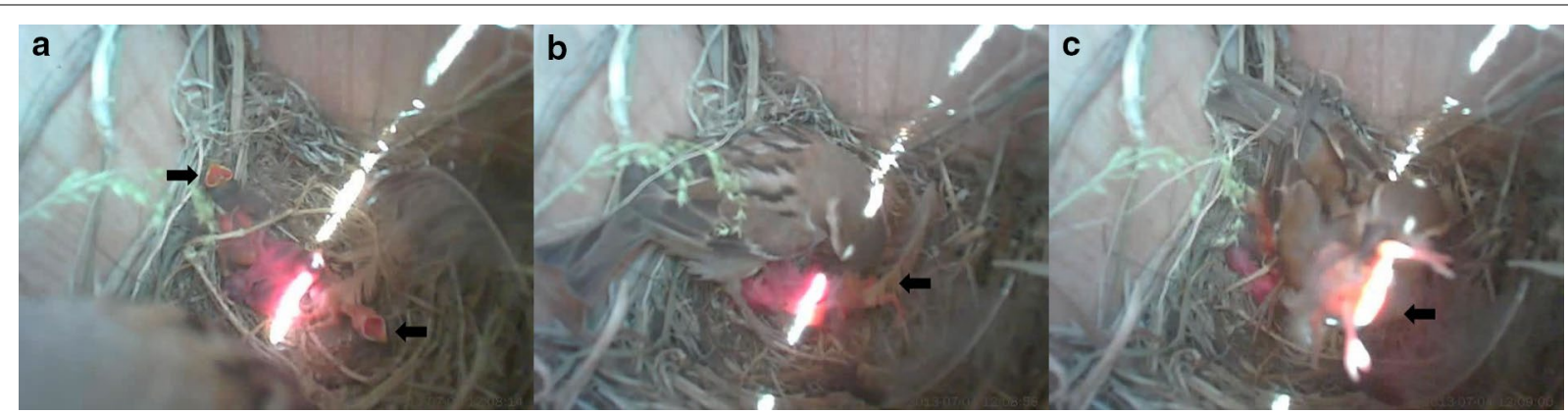

Fig. 1 Chick rejection behavior in Russet Sparrows. a Russet Sparrow nest with two bunting chicks (indicated by black arrows) and 2 Russet Sparrow chicks (between the two bunting chicks). b Russet Sparrow parents returned to the nest and started to hold a bunting chick in its beak. $\mathbf{c}$ Russet Sparrow parents ejected the bunting chick

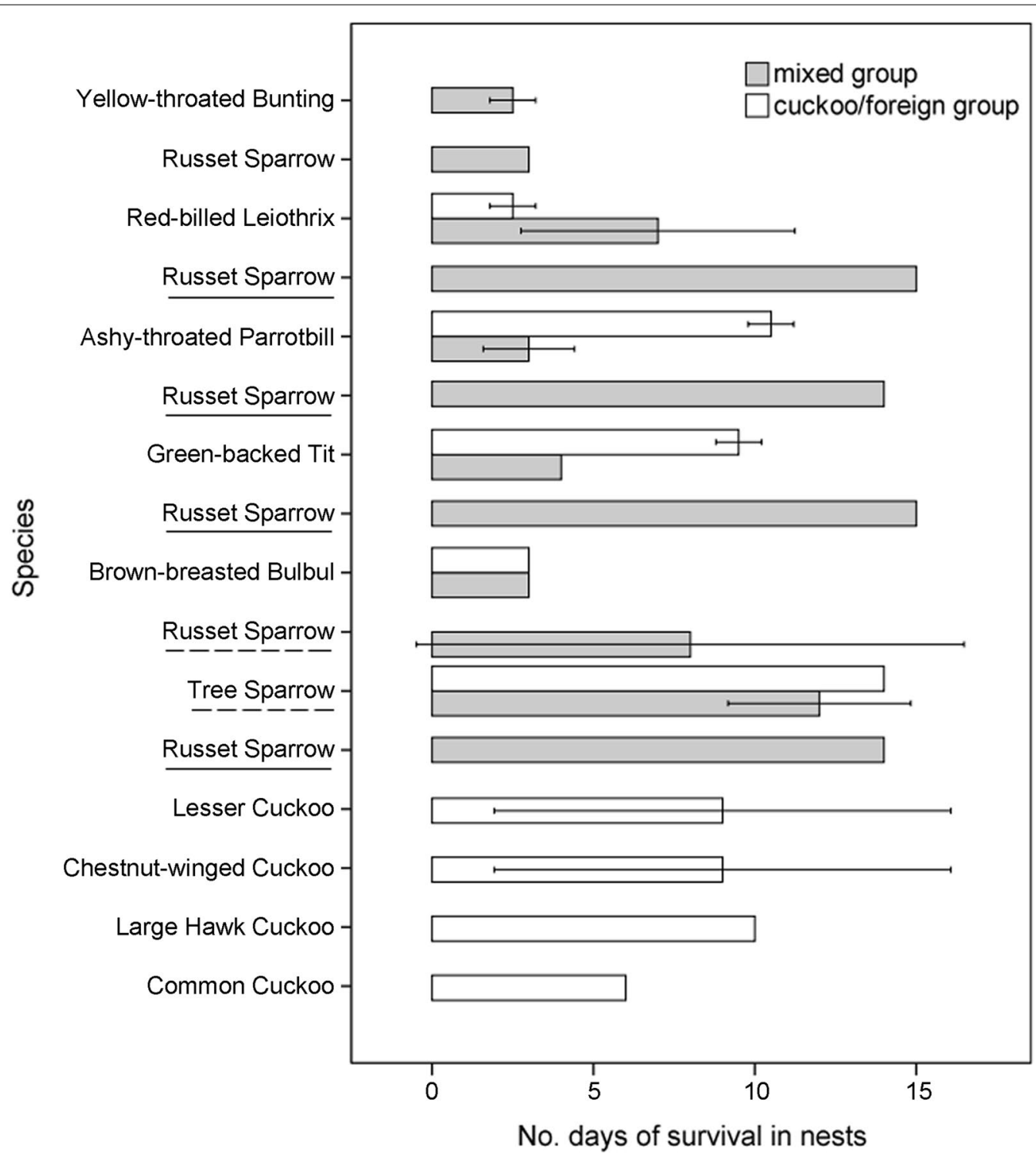

Fig. 2 Summary results for cross-fostering experiments in Russet Sparrows. Russet sparrows on $Y$-axis refer to host nestlings in mixed groups with parasite species above, respectively. Species with solid lines or without lines below indicate that they succeeded or failed to fledge, respectively. Species with dashed lines indicate that both circumstances (success or failure) exist 

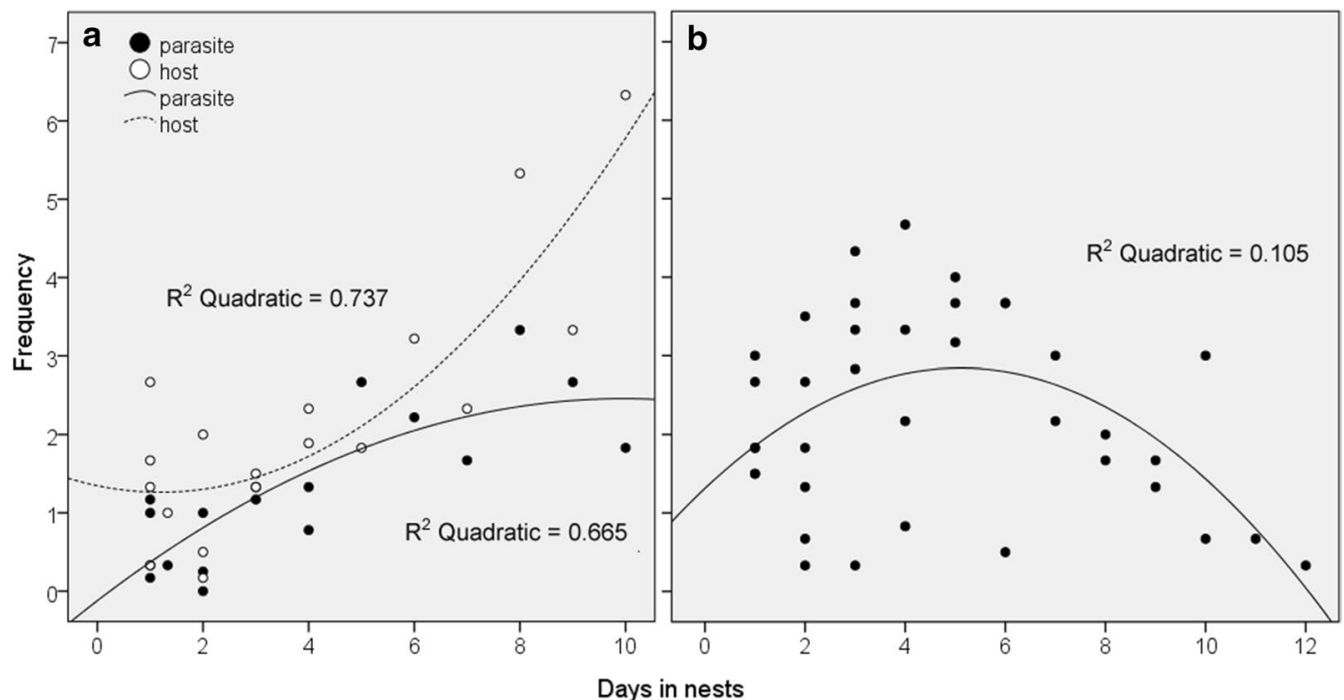

Fig. 3 Feeding frequency of nestlings in the mixed (a) and cuckoo/foreign (b) groups of cross-fostering experiments. Each dot refers to the average feeding frequency per chick per hour of parasite or host in each observed nest

\section{Discussion}

Our parasitism experiments showed that the Russet Sparrow has no egg recognition abilities. For house sparrows in Europe, although rejection of conspecific eggs was reported (Lopez de Hierro and Moreno-Rueda 2010; Soler et al. 2011; but see Yang et al. 2015a, 2016b), Manna et al. (2017) conducted parasitism experiments in different geographic populations and suggested that the House Sparrow rejection capacity was weak and negligible. In contrast, Russet Sparrow recognized and ejected model coins and sticks, which revealed a certain level of nest cleaning behavior, but lower than in host species with intermediate (e.g., Barn Swallow: 74 and 68\% for coins and sticks respectively; Yang et al. 2015c) or strong (e.g., Great Reed Warbler Acrocephalus arundinaceus: 93.1 and $93.5 \%$ for coins and sticks respectively; Moskát et al. 2003) egg rejection capacity.

Cross-fostering experiments indicated that Russet Sparrows have chick recognition abilities. According to our results, newly hatched alien chicks, which cannot produce begging calls yet, were ejected or starved to dead in sparrow nests, which implied that Russet Sparrow can identify alien chicks by visual cues. Generally in passerines, nestlings produce begging calls only after several days post-hatch (e.g., Colombelli-Négrel et al. 2012) and our observation is consistent with previous studies. However, they spend variable time of making a decision from 2 to 14 days. Therefore, both the visual and vocal contrasts between alien chicks and growing chicks of sparrows may both influence chick cognition in Russet Sparrow. Combined with previous studies, unlike egg recognition that occurs very fast (generally less than 3 days), chick recognition shows large variation (Langmore et al. 2003: 3-6 days; Grim et al. 2003: ca. 14 days). Furthermore, Russet Sparrows reject alien chicks in all cross-fostered groups, which indicated that they do not need their own chicks as comparison (see also Grim 2006). Similarly, previous studies also indicated that generally hosts do not need their own eggs as comparison for alien egg rejection (Moskát and Hauber 2007; Wang et al. 2015, but see Yang et al. 2014). One case of three Tree Sparrows succeeded to fledge from a host nest, which may be explained by the similarity between their chicks because they are closely related sister-species (Jetz et al. 2012). Additionally, two cases of Russet Sparrows in mixed groups also failed to fledge, which implied that recognition error may exist. For example, Sato et al. (2010) reported chick recognition error in the Largebilled Gerygone (Gerygone magnirostris) host when they rejected the Little Bronze-cuckoo (Chrysococcyx minutillus) nestlings, whilst few studies revealed recognition error (Grim et al. 2003; Langmore et al. 2003; Yang et al. 2015b). Further studies are needed in the future to test these presumptions.

Although initial study suggested that chick recognition is maladaptive and difficult to evolve (Lotem 1993), an increasing number of studies have shown that chick recognition can evolve as an adaptation toward brood parasitism (Grim et al. 2003; Langmore et al. 2003; Grim 2011; Yang et al. 2015b). However, chick recognition is not as common as egg recognition, and this may be explained by the rarer enemy hypothesis which suggests 
that chick recognition is prone to evolve only in hosts without egg recognition as a consequence of a release from a selection pressure against parasites at an earlier developmental stage, i.e., egg stage (Grim 2006).

In summary, our studies showed that Russet Sparrows have no egg recognition ability, but recognize their own nestlings and eject alien chicks or starve them to death. By rejecting nestlings of foreign species, Russet Sparrows have succeeded to escape from the brood parasitism by cuckoos and other parasites.

\section{Conclusions}

This study showed that Russet Sparrows have no egg recognition ability, but recognize their own nestlings and eject alien chicks or starve them to death. They may use visual cues in chick discrimination, although they accept sister species Tree Sparrows. By rejecting nestlings of foreign species, Russet Sparrows have succeeded to escape from the brood parasitism by cuckoos and other parasites. The present study shed light on the puzzle why some species are not utilized by cuckoo parasites as hosts, and perhaps that Asian hosts are becoming a great model for the study of parasite-host coevolution. In addition, our study highlighted the necessity to test in more host species for chick discrimination (ideally those that are known egg acceptors-see the rarer enemy effect, Grim 2006).

\section{Authors' contributions}

WL and $\mathrm{CY}$ conceived and designed the experiment, JH and TS conducted the experiments and collected field data. APM provided new ideas for this manuscript. JH and CY performed data analyses and wrote an early version of the manuscript. WL and APM revised and improved the manuscript. All authors read and approved the final manuscript.

\section{Author details}

${ }^{1}$ Ministry of Education Key Laboratory for Ecology of Tropical Islands, College of Life Sciences, Hainan Normal University, Haikou 571158, China. ${ }^{2}$ College of Forestry, Guangxi University, Nanning 530004, China. ${ }^{3}$ Ecologie Systématique Evolution, Université Paris-Sud, CNRS, AgroParisTech, Université ParisSaclay, 91405 Orsay Cedex, France.

\section{Acknowledgements}

We thank Junqiu Wu, Guoxian Liang, and Ping Ye for their assistance with fieldwork, and the help and cooperation from Kuankuoshui National Nature Reserves. We are grateful to two anonymous reviewers for providing constructive and valuable comments that significantly improved the quality of the manuscript.

\section{Competing interests}

The authors declare that they have no competing interests.

\section{Availability of data and materials}

The datasets used in the present study are available from the corresponding author on reasonable request.

\section{Consent for publication}

Not applicable.

\section{Ethics approval}

The experiments comply with the current laws of China where they were performed. Ethical concerns were given the highest priority and we kept sample sizes of the cross-fostering experiment to a minimum (Taborsky 2010; Grim et al. 2011). Experimental procedures were in agreement with the Animal Research Ethics Committee of Hainan Provincial Education Centre for Ecology and Environment, Hainan Normal University (permit no. HNECEE-2011-002). Fieldwork was carried out under the permission from Kuankuoshui National Nature Reserves, China. Experiments, including cross-fostering of chicks, were carried out following standard protocols widely used in similar studies (Yang et al. 2013, 2016b).

\section{Funding}

This work was supported by the National Natural Science Foundation of China (Nos. 31672303 to CY, 31472013 and 31772453 to WL).

Received: 8 June 2017 Accepted: 18 March 2018

Published online: 28 March 2018

\section{References}

Allende LM, Rubio I, Ruíz-del-Valle V, Guillén J, Martínez-Laso J, Lowy E, Varela P, Zamora J, Arnaiz-Villena A. The Old world sparrows (Genus Passer) phylogeography and their relative abundance of nuclear mtDNA pseudogenes. J Mol Evol. 2001;53:144-54.

Baumgartner AM. Food and feeding habits of the tree sparrow. Wilson Bull. 1937:49:65-80

Briskie JV, Sealy SG, Hobson KA. Differential parasitism of least flycatchers and yellow warblers by the brown-headed cowbird. Behav Ecol Sociobiol. 1990:27:403-10.

Colombelli-Négrel D, Hauber ME, Robertson J, Sulloway FJ, Hoi H, Griggio M, Kleindorfer S. Embryonic learning of vocal passwords in superb fairywrens reveals intruder cuckoo nestlings. Curr Biol. 2012;22:1-6.

Davies NB. Cuckoo, cowbirds and other cheats. London: T\& AD Poyser; 2000.

Davies NB, Brooke M de L. Cuckoos versus reed warblers: adaptations and counteradaptations. Anim Behav. 1988;36:262-84.

Davies NB, Welbergen JA. Social transmission of a host defense against cuckoo parasitism. Science. 2009;324:1318-20.

De Mársico MC, Gantchoff MG, Reboreda JC. Host-parasite coevolution beyond the nestling stage? mimicry of host fledglings by the specialist screaming cowbird. Proc R Soc B. 2012;279:3401-8.

Deng W. Brood parasitism on yellow-rumped flycatcher (Ficedula zanthopygia) by the Oriental cuckoo (Cuculus optatus) in an artificial nestbox in Beijing. Chin Birds. 2013;4:187-8.

Feeney WE, Welbergen JA, Langmore NE. The frontline of avian brood parasitehost coevolution. Anim Behav. 2012;84:3-12

Girard J, Baril A, Mineau P, Fahrig L. Foraging habitat and diet of song sparrows (Melospiza melodia) nesting in farmland: a stable isotope approach. Can J Zool. 2012;90:1339-50.

Grim T. The evolution of nestling discrimination by hosts of parasitic birds: why is rejection so rare? Evol Ecol Res. 2006;8:785-802.

Grim T. Experimental evidence for chick discrimination without recognition in a brood parasite host. Proc R Soc B. 2007;274:373-81.

Grim T. Ejecting chick cheats: a changing paradigm? Front Zool. 2011;8:14.

Grim T, Kleven O, Mikulica O. Nestling discrimination without recognition: a possible defence mechanism for hosts towards cuckoo parasitism? Proc $R$ Soc B. 2003;270:S73-5.

Grim T, Samaš P, Moskát C, Kleven O, Honza M, Moksnes A, Røskaft E, Stokke BG. Constraints on host choice: why do parasitic birds rarely exploit some common potential hosts? J Anim Ecol. 2011;80:508-18.

Grim T, Samaš P, Procházka P, Rutila J. Are tits really unsuitable hosts for the common cuckoo? Ornis Fenn. 2014;91:166-77.

Guigueno MF, Sealy SG. Nest sanitation in passerine birds: implications for egg rejection in hosts of brood parasites. J Ornithol. 2012;153:35-52.

Jetz W, Thomas GH, Joy JB, Hartmann K, Mooers AO. The global diversity of birds in space and time. Nature. 2012:491:444-8.

Kilner RM, Langmore NE. Cuckoo versus hosts in insects and birds: adaptations, counter-adaptations and outcomes. Biol Rev. 2011:86:836-52.

Langmore NE, Hunt S, Kilner RM. Escalation of a coevolutionary arms race through host ejection of brood parasitic young. Nature. 2003;422:157-60. 
Li D, Zhang Z, Grim T, Liang W, Stokke BG. Explaining variation in brood parasitism rates between potential host species with similar habitat requirements. Evol Ecol. 2016;30:905-23.

Liang W, Yang C, Wang L, Møller AP. Avoiding parasitism by breeding indoors: cuckoo parasitism of hirundines and rejection of eggs. Behav Ecol Sociobiol. 2013;67:913-8.

Liang W, Møller AP, Stokke BG, Yang C, Kovařík P, Wang H, Yao C-T, Ding P, Lu X Moksnes A, Røskaft E, Grim T. Geographic variation in egg ejection rate by great tits across 2 continents. Behav Ecol. 2016;27:1405-12.

Lopez de Hierro MDG, Moreno-Rueda G. Egg-spot pattern rather than egg colour affects conspecific egg rejection in the house sparrow (Passer domesticus). Behav Ecol Sociobiol. 2010;64:317-24.

Lotem A. Learning to recognize nestling is maladaptive for cuckoo Cuculus canorus hosts. Nature. 1993;362:743-4.

Manna T, Cooper C, Baylis S, Shawkey MD, Waterhouse GIN, Grim T, Hauber ME. Does the house sparrow Passer domesticus represent a global model species for egg rejection behavior? J Avian Biol. 2017;48:346-52.

Marchetti K. Egg rejection in a passerine bird: size does matter. Anim Behav. 2000;59:877-83.

Mlíkovský J. Correct name for the Asian russet sparrow. Chin Birds. 2011;2:109-10.

Moksnes A, Røskaft E. Egg-morphs and host preference in the common cuckoo (Cuculus canorus): an analysis of cuckoo and host eggs from European museum collections. J Zool. 1995;236:625-48.

Moskát C, Hauber ME. Conflict between egg recognition and egg rejection decisions in common cuckoo (Cuculus canorus) hosts. Anim Cogn. 2007;10:377-86.

Moskát C, Székely T, Kisbenedek T, Karcza Z, Bártol I. The importance of nest cleaning in egg rejection behaviour of great reed warblers Acrocephalus arundinaceus. J Avian Biol. 2003;34:16-9.

Rothstein SI. An experimental and teleonomic investigation of avian brood parasitism. The Condor. 1975;77:250-71.

Samaš P, Rutila J, Grim T. The common redstart as a suitable model to study cuckoo-host coevolution in a unique ecological context. BMC Evol Biol. 2016;16:255.

Sato NJ, Tokue K, Noske RA, Mikami OK, Ueda K. Evicting cuckoo nestlings from the nest: a new anti-parasitism behaviour. Biol Lett. 2010;6:67-9.

Seel DC. Food, feeding rates and body temperature in the nestling house sparrow Passer domesticus at Oxford. Ibis. 2008;111:36-47.

Soler M. Long-term coevolution between avian brood parasites and their hosts. Biol Rev. 2014;89:688-704.

Soler M, Ruiz-Castellano C, Fernández-Pinos MC, Rösler A, Ontanilla J, Pérez-Contreras T. House sparrows selectively eject parasitic conspecific eggs and incur very low rejection costs. Behav Ecol Sociobiol. 2011;65:1997-2005.
Spottiswoode CN, Stevens M. Visual modeling shows that avian host parents use multiple visual cues in rejecting parasitic eggs. Proc Natl Acad Sci USA. 2010;107:8672-6.

Starling M, Heinsohn R, Cuckburn A, Langmore NE. Cryptic gentes revealed in pallied cuckoos Cuculus pallidus using reflectance spectrophotometry. Proc R Soc B. 2006;273:1929-34.

Stoddard MC, Stevens M. Avian vision and the evolution of egg color mimicry in the common cuckoo. Evolution. 2011;65:2004-13.

Taborsky M. Sample size in the study of behaviour. Ethology. 2010;116:185-202.

Wang L, Yang C, Møller AP, Liang W, Lu X. Multiple mechanisms of egg recognition in a cuckoo host. Behav Ecol Sociobiol. 2015;69:1761-7.

Yang C, Liang W, Cai Y, Shi SH, Takasu F, Møller AP, Antonov A, Fossøy F, Moksnes A, Røskaft E, Stokke BG. Coevolution in action: disruptive selection on egg colour in an avian brood parasite and its host. PLoS ONE. 2010:5:e10816.

Yang C, Liang W, Cai Y, Wu J, Shi S, Antonov A. Variation in russet sparrow (Passer cinnamomeus) breeding biology in relation to small-scale altitudinal differences in China. Zool Sci. 2012a;29:419-22.

Yang C, Liang W, Antonov A, Cai Y, Stokke BG, Fossøy F, Moksnes A, Røskaft E. Diversity of parasitic cuckoos and their hosts in China. Chin Birds. 2012b;3:9-32.

Yang C, Stokke BG, Antonov A, Cai Y, Shi S, Moksnes A, Røskaft E, Møller AP, Liang W, Grim T. Host selection in parasitic birds: are open-cup nesting insectivorous passerines always suitable cuckoo hosts? J Avian Biol. 2013:44:216-20.

Yang C, Møller AP, Røskaft E, Moksnes A, Liang W, Stokke BG. Reject the odd egg: egg recognition mechanisms in parrotbills. Behav Ecol. 2014;25:1320-4.

Yang C, Hu Y, Ma M, Liang W, Møller AP. Absence of egg rejection in an Asian population of house sparrow (Passer domesticus), a conspecific brood parasite in Europe. Behav Ecol Sociobiol. 2015a;69:723-7.

Yang C, Wang L, Chen M, Liang W, Møller AP. Nestling recognition in redrumped and barn swallows. Behav Ecol Sociobiol. 2015b;69:1821-6.

Yang C, Wang L, Liang W, Møller AP. Nest sanitation behavior in hirundines as a pre-adaptation to egg rejection to counter brood parasitism. Anim Cogn. 2015c;18:355-60.

Yang C, Wang L, Liang W, Møller AP. Egg recognition as antiparasitism defence in hosts does not select for laying of matching eggs in parasitic cuckoos. Anim Behav. 2016a;122:177-81.

Yang C, Wang L, Liang W, Møller AP. Contrasting egg recognition between European and Asian populations of tree sparrows (Passer montanus). Behav Proc. 2016b;125:85-8.

\section{Submit your next manuscript to BioMed Central and we will help you at every step:}

- We accept pre-submission inquiries

- Our selector tool helps you to find the most relevant journal

- We provide round the clock customer support

- Convenient online submission

- Thorough peer review

- Inclusion in PubMed and all major indexing services

- Maximum visibility for your research

Submit your manuscript at www.biomedcentral com/submit
BioMed Central 